\title{
IR camera and pyrometer used for woodworking control
}

\author{
by M. Kastek ${ }^{1}$, H. Madura ${ }^{1}$, H. Polakowski ${ }^{1}$ and W. Sokołowski ${ }^{2}$ \\ ${ }^{1}$ Military University of Technology, 2 S. Kaliski St. 01-489 Warsaw, Poland \\ ${ }^{2}$ Warsaw Agricultural University, Wood Technology Faculty 26/30 Rakowiecka St., 02-528 Warsaw, \\ Poland
}

\begin{abstract}
Similarly to metal cutting machines, also wood cutting machines can be also equipped with automatic devices for determination of tools conditions. This paper presents one of the methods used for determination of limits of woodworking parameters or admissible wear of blades of cutting tools. The paper includes results of measurements of woodworking process continuo measurement of a surface temperature by means of an IR camera and a pyrometer.
\end{abstract}

\section{Introduction}

Similarly to metal cutting machines, also wood cutting machines can be equipped with automatic devices for determination of tools conditions. This paper presents one of the methods used for determination of limits during a woodworking parameters or admissible wear of blades of cutting tools.

Determination of tool blade wear during a cutting process is extremely difficult. As we know there is a close relation between the cutting process temperature and the degree of blade's wear. Temperature measurement of the tool blade which is used for woodworking may by an appropriate factor of the process control.

During machine cutting the balance between the temperature of tool blade and the temperature of the worked material surface is observed. A temperature measurement of the worked material enables determination of the temperature and of the technical conditions (degree of wear) of a cutting tool [1].

The paper includes results of measurements during a woodworking process continuo of a surface temperature by means of an IR camera and a pyrometer.

\section{Measurements of temperature changes by means of IR camera}

Figure 1 presents the experimental set up. The camera is situated next to the milling machine and its optical axis covers the working plane of a cutting tool. The worked elements were moved by means of a cylindrical, universal feed mechanism along a guide, which was made for the experiment. In the guide a rectangular hole was drilled for observation of the treated surface just behind a milling cutter.

IR Inframetrics 760 camera was used for the measurements. The chosen images of temperature area (for temperature range from $17,9^{\circ} \mathrm{C}$ to $29,3^{\circ} \mathrm{C}$ with accuracy $\pm 0.2^{\circ} \mathrm{C}$ ) were registered on a videotape and in a computer memory.

In the analysis of termovision images the temperatures distribution was registered on a line parallel to feed direction, in the working plane of the cutting toll (i.e., half-way thickness of the worked element).

Figure 2 presents temperatures distribution on the worked wooden board with the use of a sharp and blunt blade. The measurements were carried out for the same type of wood and at the same cutting velocity and rate of travel of the worked board. The results of experiment showed a considerable temperatures difference of the worked surface with the use of a sharp or blunt blade. Thus measurement of temperatures distribution can be applied for determination of technical condition of a tool while woodworking or other wooden materials treatment [2]. 
For temperature determination in diagnosis IR pyrometer can be used. Such pyrometer is cheaper than IR camera. Pyrometer parameters must be adequate for travel rate of the worked material and small measurement area should be only near the cutting tool. Due to high degree of dust the pyrometer should be protected from it by applying additional supply ventilation for pyrometer lens.

Furthermore, the pyrometer should be fixed in another arrangement than the woodworking machine one so that it should not undergo machine vibrations. Picture 1 presents the pyrometer constructed for woodworking process control.

\section{Temperature measurement by means of pyrometer}

For the experiments a pyrometer constructed on the basis of smart measuring head and software of RAYTEK were used. The pyrometer allows for remote temperature measurement with accuracy $1 \%$ and resolution of $0.1^{\circ} \mathrm{C}$. Diameter of measuring area is $6,4 \mathrm{~mm}$ (at a distance of $200 \mathrm{~mm}$ ). Spectral range of the device is within $8-14 \mu \mathrm{m}$, that significantly eliminates the influence of external disturbances on the accuracy of measurement. Additionally, the pyrometer was equipped with laser diodes $(670 \mathrm{~nm})$ indicating precisely the place of measuring area and autonomous air ventilation on optical elements allows for proper work of the device dustiness. Picture 2 shows the pyrometer on the measuring position.

Temperature measurements were carried out while milling fibreboard of medium density (MDF). The large width (thickness) of shavings causes disturbances of the cutting process because of additional material squashing by the shavings. As a result of material squashing and at the same increase in power of a friction force additional heat is produced. The aim of experiments was to determine the influence of the shavings width on temperature of the worked surface.

Figure 3 presents heating of worked surface as cutting distance increases while milling MDF with the use of tools with the same blades of various values of shavings width. Figure 4 presents the change of medium temperature depending on the shavings width [1].

Temperature measurements of the worked surface obtained by the use of pyrometer indicate that it is possible to determine the degree of tool's wear as well as to establish permissible values of cutting process. Temperature value of the worked surface can be the basic signal for automatic control system of woodworking and at the same allows for wood working control.

\section{Conclusions}

The experiments have shown usefulness of IR pyrometer for continuos temperature measurements of the worked surface while milling wood and wooden materials. Additionally it was concluded that temperature measurement of the worked surface only is not sufficient perameter. For example in experiments of shavings width influence of tool with the same blades on the temperature of the worked surface determination of adequate shavings width for proper cutting process be confirmed by experiment results of cutting forces distribution. Only then it is possible to provide exact data for practical application tools with the same blades application.

The experiments have also shown that as tools wear increases, the temperature of the worked surface increases as well. It is obvious, and carpenters commonly know this phenomenon. Work with blunt tool causes burns and even carbonisation of the worked elements. The application of IR pyrometers for determination of limits of cutting tools wear allows for automation of this process. Temperature of the worked surface and values of cutting forces are optimum input signals for smart systems of woodworking monitoring and in particular for determination of limits of a blades wear of cutting tool.

Further experiments are planned, the purpose of which is the determination of the influence of blades wear degree on the temperature of the worked surface. The developed infrared pyrometer will be used to determine temperature values. 


\section{REFRENCES}

[1] MADURA (H.), POLAKOWSKI (H.), KASTEK (M.) - Diagnostyka procesu obróbki drewna metodami radiometrycznego pomiaru temperatury. Pomiary Automatyka Kontrola, 1996.

[2] SOKOKOWSKI (W.) - Zastosowanie kamery termowizyjnej w badaniach procesu obróbki drewna i tworzyw drzewnych. V Konferencja Naukowo - Techniczna. Obróbka Matriałów Niemetalowych NM '95. Rzeszów, październik 1995.

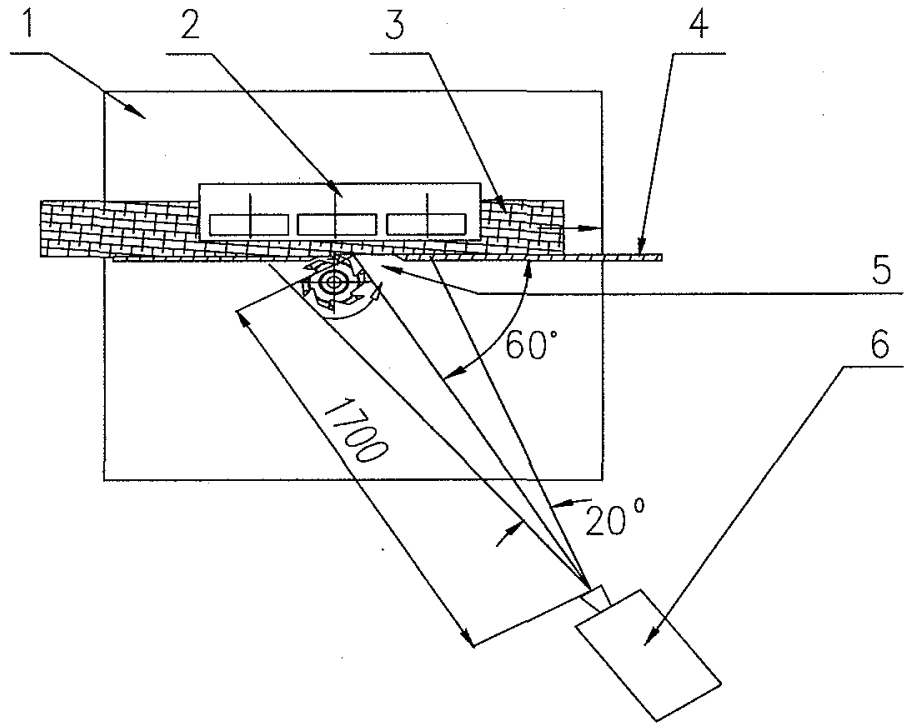

Fig. 1. Control stand: 1-milling machine, 2-feed mechanism, 3-worked element, 4guide, 5-slot for observation of the treated surface, 6-IR camera

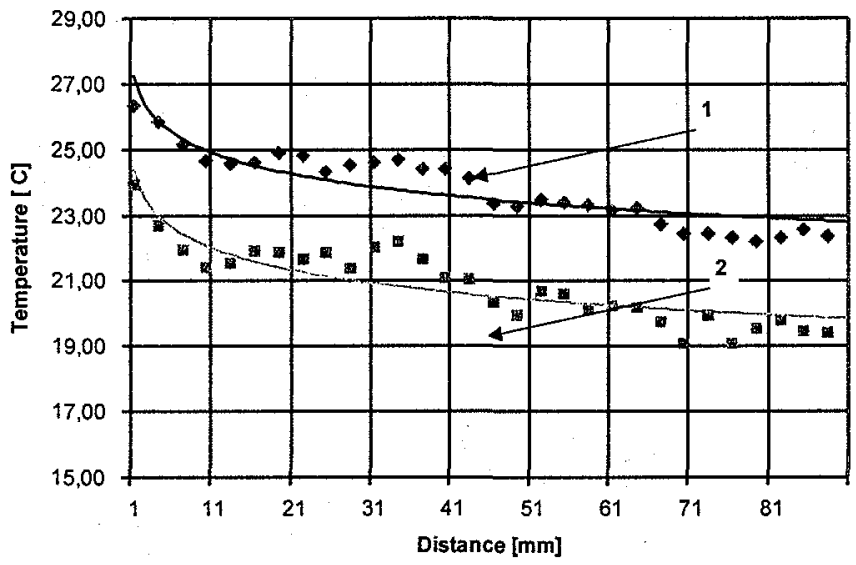

Fig. 2. Temperature of the surface of worked wood measured close the cutting tool: 1-blunt tool 2-sharp tool 
http://dx.doi.org/10.21611/qirt.1998.031

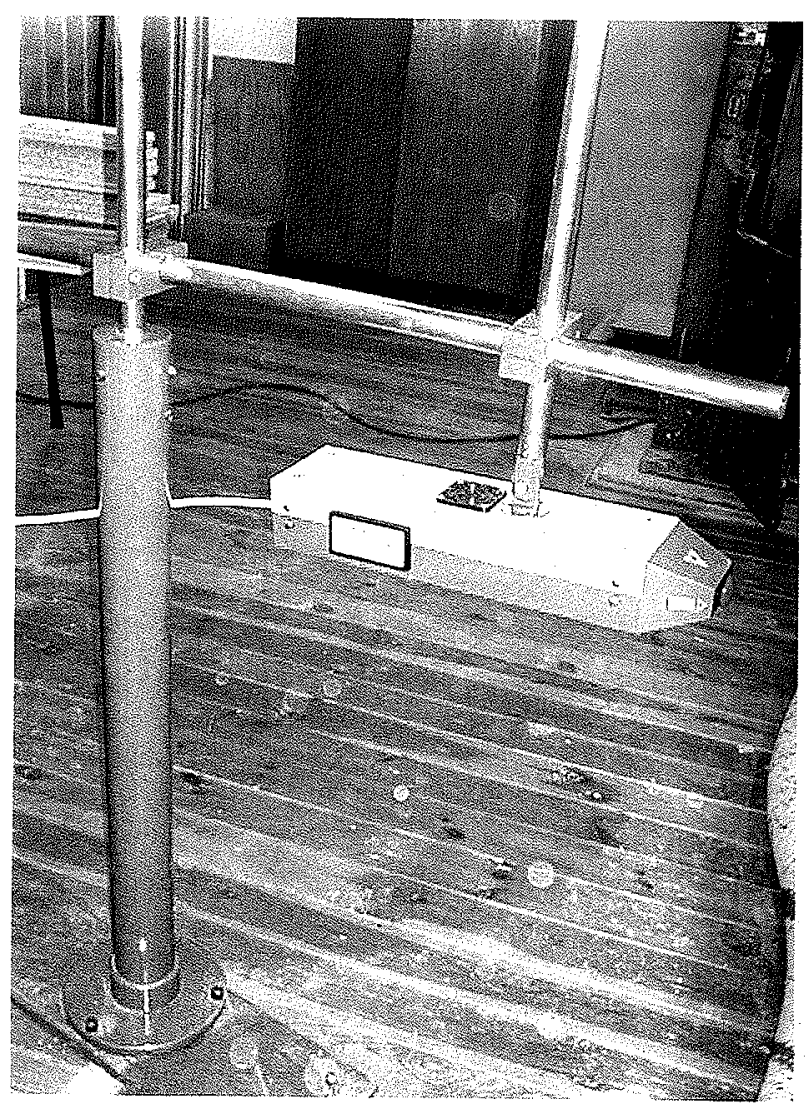

Fig. 1. IR pyrometer constructed for woodworking process control

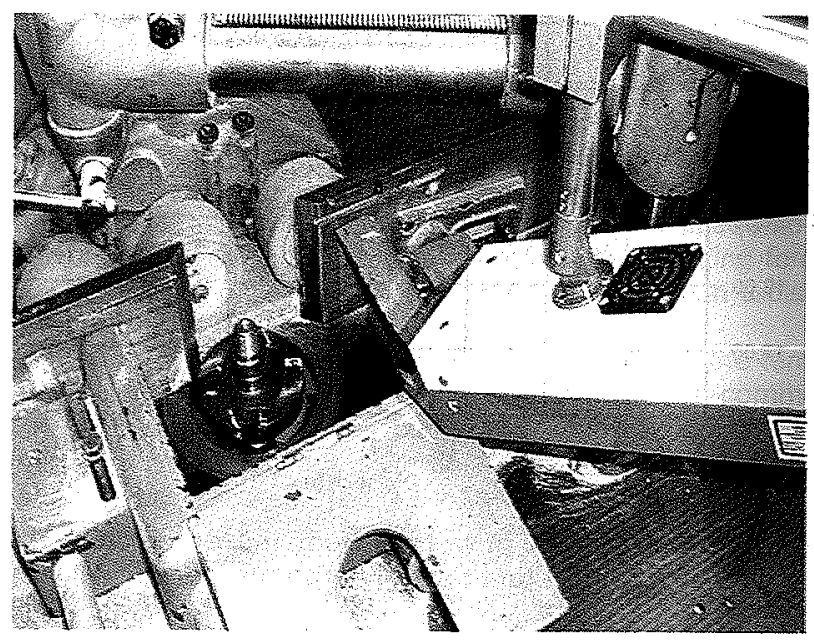

Fig. 2. IR pyrometer on the measuring position 
http://dx.doi.org/10.21611/qirt.1998.031

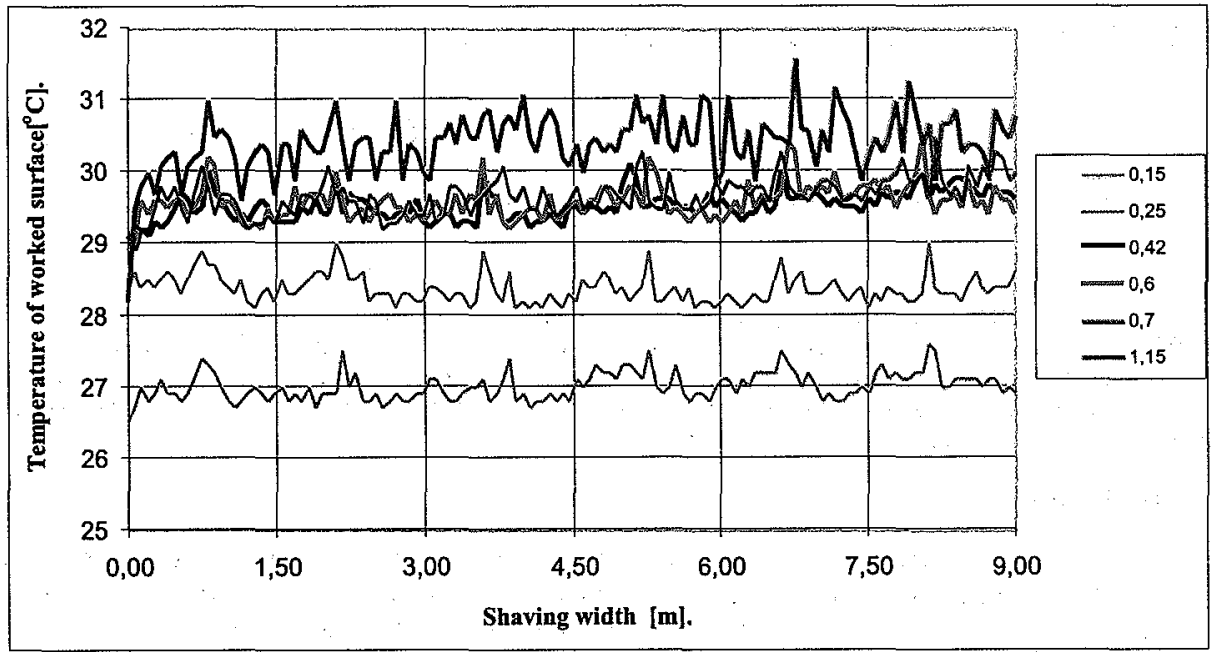

Fig. 3. Relation between the value of shaving width and the temperature of worked surface

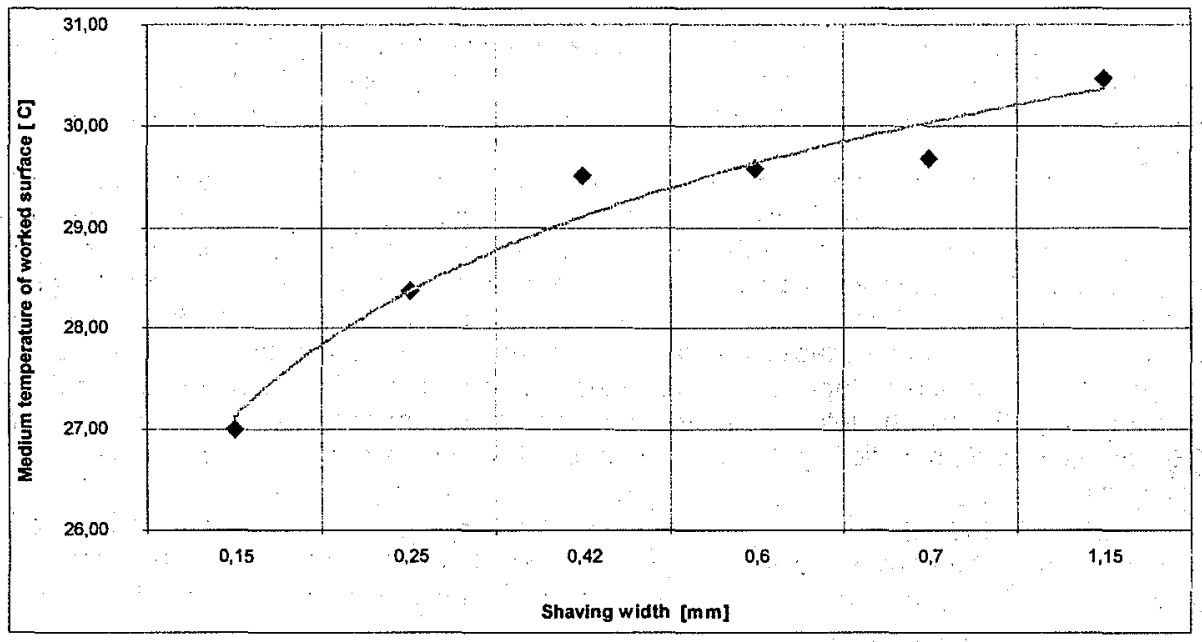

Fig. 4. Relation between the value of shaving width and the medium temperature of worked surface 